\title{
The Canonical Order of Russian Objects
}

\author{
Elena Titov
}

According to the principles of economy, scrambled orders require an interpretive license. Removal of such a license should result in canonical orders, that is, orders I hypothesize to be determined by a thematic hierarchy. It is traditionally assumed that the interpretive license for scrambling is provided by information-structural interpretations such as focus and background. However, either direct object-indirect object or indirect object-direct object order is possible in Russian all-focus constructions, complicating the choice of order analyzed as canonical. I argue that Russian scrambling can be licensed by a variety of interpretations, focus/background encoding being but one of them. When the construal of objects is neutralized on the basis of all of the relevant interpretations, the direct object-indirect object order surfaces, strongly suggesting that this is the canonical order of Russian objects.

Keywords: Russian ditransitive constructions, canonical order of objects, scrambling, information structure

\section{Introduction}

The nature of the canonical order of Russian objects has been a matter of continuous debate in the linguistic literature. Several syntactic analyses have been proposed that claim to demonstrate that either direct object-indirect object (O-IO) or indirect object-direct object (IO-O) order should be analyzed as canonical in Russian. For instance, Bailyn $(2010,2012)$ defends the hypothesis that $\mathrm{O}-\mathrm{IO}$ is the unmarked order of Russian objects and backs it up with data involving instrumental secondary predicates, reciprocal and variable binding, and scope. Dyakonova (2007, 2009), on the other hand, uses evidence from idiom formation and topicalization to argue for the opposite view. ${ }^{1}$

The aim of this article is to offer new, interpretive support for O-IO as the canonical order of Russian objects and hence to supplement syntactic arguments for the same result and put pressure on accounts that claim the IO-O order is more basic.

Many thanks to Gisbert Fanselow, Kriszta Szendrői, Hans van de Koot, Matthew Reeve, and the anonymous reviewers for detailed comments on the material presented here. I would also like to thank Mira Grubic, Anne Mucha, Simone Pfeil, and Marta Wierzba for German judgments. Material from this article was presented at LAGB 2013 and the SynSem Colloquium that took place at the University of Potsdam on 26 November 2013. I would like to thank the audiences for useful comments.

${ }^{1}$ The idea that Theme is higher than Goal on the thematic hierarchy is also defended in Larson 1988, AntonyukYudina 2010, and Titov 2012b, whereas the view that the direct object merges with the verb first and the indirect object is generated higher up has been argued for in Chvany 1975, Junghanns and Zybatow 1995, Pereltsvaig 2003, Soschen 2005, and Slioussar 2007. The present analysis assumes that the thematic hierarchy is universal. 
The core assumption adopted here is that syntax is capable of creating not only simple structures with the canonical/neutral order of objects (i.e., the order determined by the thematic hierarchy) but also more complex scrambled constructions where the order of objects is reversed. ${ }^{2}$ However, the scrambled construction must be analyzed as marked with respect to the canonical structure. There are various ways of accounting for the marked nature of the scrambled structure. If we assume that scrambling involves movement of one object across the other, we can argue that the scrambled structure is more costly than the canonical structure because it involves an additional movement operation. But even if we assume that both object orders are base-generated in Russian, as has been argued for several other Slavic languages (e.g., Croatian, Bulgarian, Czech, and Slovenian; for discussion, see Bruening 2001, Cuervo 2003, Gračanin-Yuksek 2006, Pylkkänen 2008, Slavkov 2008, Dvořák 2010, Marvin and Stegovec 2012), we can still argue that the base-generated scrambled structure is marked with respect to the canonical structure because the former involves an inverse order of $\theta$-role assignment, which makes it more costly (Neeleman and van de Koot 2012). ${ }^{3}$

Assuming that syntax produces marked structures along with unmarked ones, at the interface between the syntactic component and the interpretive component-that is, the postgrammatical level of discourse (Reinhart 1995, 2006) - interface economy rules operate that ban more complex marked structures unless the marked construction achieves an interpretive effect that the simpler unmarked structure fails to express. This basic concept of interface economy is not new and has been discussed quite extensively (see Reinhart 1995, 1999, 2004, 2006, Neeleman and Reinhart 1998, Neeleman and van de Koot 2008, 2012), but it offers a novel means of testing which object order is canonical in Russian. That is, if the marked (i.e., scrambled) construction can only surface to capture a specific interpretive effect, removal of this interpretive effect will leave us with the canonical structure. Let us now investigate what this specific interpretive effect is.

The proposal advanced here is that the relevant effect has to do with the relative interpretive prominence of objects. ${ }^{4}$ By hypothesis, the interpretive component contains the well-formedness constraint given in (1). That is, there is a requirement for interpretively prominent material to precede interpretively nonprominent material.

(1) $[+$ prominent $]>[-$ prominent $]$

The constraint in (1) represents the principle of Communicative Dynamism (Firbas 1964, 1971, 1984, 1992, Sgall, Hajičová, and Panevová 1986). According to this principle, material that is contextually prominent (e.g., in virtue of being present in the context) precedes material that conveys information not (yet) prominent in the discourse.

\footnotetext{
${ }^{2}$ Canonical orders are taken here to be orders that are not obscured by the encoding of an optional interpretation. By neutralizing all optional interpretations that regulate the order of Russian objects, we are left with the order determined by an interpretation that is always operative. By hypothesis, the relevant interpretation is thematic interpretation. However, we cannot fully dismiss the possibility that the canonical order of arguments is determined by some entirely different, as yet unknown factor.

${ }^{3}$ In this article, I adopt the approach to thematic assignment developed in Neeleman and van de Koot 2002.

${ }^{4}$ The analysis of Russian scrambling as licensed by the relative interpretive prominence of arguments entails that the interpretation of nonarguments plays no role in such licensing and is therefore free.
} 
In the following section, we will look in detail at the interpretations on the basis of which the relative interpretive prominence of objects is established in Russian (and possibly in other languages). For the time being, let us assume that at the interface between the syntactic and the interpretive components a mapping rule operates that demands transparent mapping of syntactic structures onto the template in (1).

Taking as a starting point the idea that O-IO is the canonical order of Russian objects, we expect the structure with this order to capture the majority of possible configurations related to the relative interpretive prominence of objects (see (2)). After all, we have assumed that this is the unmarked structure that is chosen over the marked structure by the interface economy rules for its simplicity. We do, however, expect the unmarked structure to fail to capture one specific interpretation, in which case interface economy rules allow for the cheapest unmarked structure to be replaced with a more costly marked construction (see (3)), as long as the marked construction captures exactly the interpretation that the unmarked construction fails to express.

(2) a. $\mathrm{O}_{[+ \text {prominent }]} \mathrm{IO}_{[- \text {prominent }]}$

b. $\mathrm{O}_{[+ \text {prominent }]} \mathrm{IO}_{[+ \text {prominent }]}$

c. $\mathrm{O}_{[- \text {prominent }]} \mathrm{IO}_{[- \text {prominent }]}$

d. $* \mathrm{O}_{[- \text {prominent }]} \mathrm{IO}_{[+ \text {prominent }]}$

(3) $\quad \mathrm{IO}_{[+ \text {prominent }]} \mathrm{O}_{[- \text {prominent }]}$

When it comes to the relative interpretive prominence of objects, the four configurations given in (2) are in principle possible. However, the mapping rule that requires transparent mapping onto (1) can be satisfied by the unmarked structure in (2) in only three out of four cases. The configuration in (2a) maps transparently onto (1). The configurations in $(2 b-c)$ vacuously satisfy the mapping rule, as they encode no relative interpretive prominence. That is, both objects are either prominent or nonprominent. The only configuration that cannot map transparently onto (1) or vacuously satisfy the mapping rule is the one in (2d), as this structure requires twisted mapping. ${ }^{5}$ The structure in $(2 \mathrm{~d})$ is therefore rejected by the interface system, as it does not linearly represent the correct partitioning into prominent and nonprominent material. In this case (and this case alone), the unmarked structure can be replaced by the marked structure that maps transparently onto (1), namely, (3).

Now that the mechanism regulating the correspondence between syntactic representations and available prominence configurations has been outlined, we can look more closely at the interpretations on the basis of which the relative interpretive prominence of objects is calculated. One of the most widely discussed interpretations that is capable of regulating the order of objects in Russian, as well as in many other languages, is the one that distinguishes between discourseprominent background/presupposition and discourse-new focus. In Russian, there is a tendency

\footnotetext{
5 The representations in $(2 \mathrm{a}-\mathrm{c})$ and (3) must be understood as the output of mapping the corresponding syntactic structures onto the discourse template in (1). The features given in square brackets represent discourse interpretations that objects end up being associated with after mapping. The configuration in (2d) is impossible-a so-called twisted mapping-because mapping onto (1) cannot result in objects being associated with the given discourse interpretations.
} 
for backgrounded/presupposed material to precede focused material, and, in line with this observation, an object that belongs to the background/presupposition of a sentence (in virtue of being present in the context) precedes a discourse-new focused object (see (4)). (Throughout, the word receiving the main sentential stress is boldfaced. A falling intonational contour is marked with “, and a rising contour with "', . FOC stands for focus and TOP for topic.)

(4) a. [Who did Ivan hand the/a spy to?]

Ivan peredal špiona [FOC agèntu].

Ivan handed spy.ACC agent.DAT

'Ivan handed the/a spy to the/an agent.'

b. [Who did Ivan hand to the/a agent?] CONTEXT

Ivan peredal agentu [FOC špiòna].

Ivan handed agent.DAT spy.ACC

'Ivan handed the/a spy to the/an agent.'

If we capture the interpretation that regulates the order of objects in (4) using a binary feature [ \pm presupposed] and assume that background/presupposition is [+ presupposed] and focus is [- presupposed], we can make use of the previously outlined system to account for the data in (4). ${ }^{6}$

Assuming that the mapping onto (1) is done on the basis of the [ \pm presupposed] feature in (4), as illustrated in (5), (4a) corresponds to the configuration in (6), whereas (4b) corresponds to (7). However, at this point, we can only speculate that (4a) is the unmarked canonical structure and (4b) is the marked scrambled structure, as both map transparently onto (5). What we need in order to establish which structure is canonical in (4) is either the configuration in (6b) or the one in (6c), as these configurations are only available for the unmarked structure.

(5) $[+$ presupposed $]>[-$ presupposed $]$

(6) a. $\mathrm{O}_{[+ \text {presupposed }]} \mathrm{IO}_{[- \text {presupposed }]}$

b. $\mathrm{O}_{[+ \text {presupposed }]} \mathrm{IO}_{[+ \text {presupposed }]}$

c. $\mathrm{O}_{[- \text {presupposed }]} \mathrm{IO}_{[- \text {presupposed }]}$

d. * $\mathrm{O}_{[- \text {presupposed }]} \mathrm{IO}_{[+ \text {presupposed }]}$

$$
\mathrm{IO}_{[+ \text {presupposed }]} \mathrm{O}_{[- \text {presupposed }]}
$$

\footnotetext{
${ }^{6}$ The binary features used in this article are no more than convenient labels for interpretations that a syntactic constituent is associated with as a result of mapping principles that relate syntactic structures to discourse templates. The present analysis rejects the view that syntactic representations contain features such as [focus] or [background] and assumes instead that discourse interpretations are encoded at the postgrammatical level of discourse (Reinhart 2006). Postulating discourse features in syntax requires stipulating that they are either stored in the mental lexicon or added to constituents in the course of the derivation. However, being a focus or a background is not a lexical property - a syntactic constituent can be categorized as such only when used in a specific context. Moreover, adding such features in the course of the derivation requires weakening Chomsky's (1995) Inclusiveness Condition, according to which only those features that represent properties of lexical items can figure in syntactic computations (see Szendrői 2001, Neeleman and Szendrői 2004, Den Dikken 2006, Fanselow and Lenertová 2011).
} 
It has been argued extensively that once a sentence is placed in the all-focus context of a question like What's new? or What happened?, the reply can only have the canonical order of arguments. In the present terminology, all the constituents in an all-focus sentence, including the objects, are [- presupposed], as they are all part of the focus of a sentence, resulting in the configuration in (6c).

Surprisingly, when the sentences in (4) are placed in the context of a question that licenses the configuration in (6c), both object orders are available (see (8)).

(8) [What happened?] CONTEXT

a. [FOC Ivan peredal špiona agèntu].

S-V-O-IO

Ivan handed spy.ACC agent.DAT

'Ivan handed the/a spy to the/an agent.'

b. [FOC Ivan peredal agentu špiòna].

S-V-IO-O

Ivan handed agent.DAT spy.ACC

'Ivan handed a spy to the agent.'

The observation that both orders are possible in an all-focus context, as in (8), has led to the erroneous belief that the canonical order of Russian objects cannot be established on the basis of their interpretation. However, in what follows I will demonstrate that the sentences in (8a) and (8b) have distinct information-structural (IS) partitioning, despite occurring in an all-focus context. I will maintain that Russian scrambling can be licensed by a variety of interpretations, focus/ background encoding being but one of them. All these interpretations are ranked with respect to each other, and only one of them regulates the order of objects in a given sentence. When the prominence relations of objects are neutralized on the basis of all of the interpretations that can potentially license Russian scrambling, and the order of objects is determined by the thematic hierarchy, only the O-IO order is possible, strongly suggesting that this is the canonical order of Russian objects.

The article is organized as follows. Section 2 establishes the nature of interpretations licensing Russian object-across-object scrambling and develops the mechanism of their interaction. Section 3 briefly discusses the syntax of scrambled constructions. Section 4 demonstrates that the proposed analysis has advantages over alternative approaches. Section 5 discusses the implications that the analysis has for another scrambling language, German. Section 6 concludes the article.

\section{Interpretive Restrictions on Scrambling}

Above, I have hypothesized that Russian scrambling is licensed by transparent mapping onto (1). ${ }^{7}$ However, mapping on the basis of [ \pm presupposed] cannot explain the data in (8). In particular, the interpretation of the sentences in (8) corresponds to the configuration in $(6 \mathrm{c})$ that can only

\footnotetext{
${ }^{7}$ In this article, I will abstract away from $\bar{A}$-scrambling, which is an $\bar{A}$-movement operation licensed by pragmatic quantification, such as a contrastive, generic, or emphatic/scalar reading, in Russian and other languages (see Neeleman 1994, Neeleman and van de Koot 2008, Neeleman and Titov 2009, Titov 2012a,b, 2013a).
} 
be captured by the unmarked structure. Yet both orders are possible in (8), strongly suggesting that some other interpretation regulates the order of objects and licenses a scrambled structure in (8b).

Let us consider the construal of objects in (8). Both objects in (8) are bare NPs that are not morphologically specified for definiteness or indefiniteness. ${ }^{8}$ Yet the interpretation of objects with respect to definiteness/specificity and nonspecific indefiniteness is quite different in (8a) and (8b). In particular, the objects in (8a) can be seen as having three out of the four configurations with regard to this interpretation: either both objects are interpreted as definite/specific or as nonspecific indefinites, or the direct object is definite/specific and the indirect object is a nonspecific indefinite. The only interpretation that is unavailable for (8a) is the one where the indirect object is interpreted as referring to a specific agent, whereas the direct object denotes a nonspecific spy. Crucially, this is exactly the interpretation captured by (8b) (see the determiner choice in the translation). In fact, this is the only interpretation that is available for ( $8 b)$.

Plausibly, (8) involves encoding of an interpretive feature that distinguishes definite/specific NPs from nonspecific indefinites. If we represent this interpretation using a binary feature-say, [ \pm referential] — and maintain that definite/specific NPs are [+referential], while nonspecific indefinites are [-referential], we can use the previously outlined system to account for the data in (8).

(9) $[+$ referential $]>[-$ referential $]$

(10) a. $\mathrm{O}_{[+ \text {referential }]} \mathrm{IO}_{[- \text {referential }]}$

b. $\mathrm{O}_{[+ \text {referential }]} \mathrm{IO}_{[+ \text {referential }]}$

c. $\mathrm{O}_{[- \text {referential }]} \mathrm{IO}_{[- \text {referential }]}$

d. $* \mathrm{O}_{[- \text {referential }]} \mathrm{IO}_{[+ \text {referential }]}$

$$
\mathrm{IO}_{[+ \text {referential }]} \mathrm{O}_{[- \text {referential }]}
$$

We can now argue that the structure in (8a) satisfies the mapping rule that requires transparent mapping onto (9) in three out of the four cases. Specifically, (8a) can have the interpretations in $(10 a-c)$. Conversely, the structure in $(8 b)$ can have only the interpretation in (11).

The construal of objects in (8a) is [- presupposed], as both objects are in focus. Both can have the same value with respect to [ \pm referential], suggesting that both features can be vacuously satisfied. Crucially, the order that surfaces in (8a) is O-IO, strongly suggesting that this is the canonical order of Russian objects.

Now that we have two IS features that regulate the order of Russian objects, we need to establish how they interact. To be precise, both features cannot regulate the order of objects within

\footnotetext{
${ }^{8}$ Since Russian NPs lack articles of the type found in languages like Dutch, English, and German, they also lack morphological specification for (in)definiteness, unless they are selected by deictic or possessive determiners or are accompanied by indefinite pronouns specifying different interpretations of noun phrases (see Dahl 1970, Ioup 1977). Russian bare NPs have an open interpretation with regard to definiteness/indefiniteness. Brun (2001) argues that, because morphological encoding of referentiality is lacking on bare NPs, Russian resorts to structural encoding. A way of capturing this observation is to say that referentiality is one of the interpretations operating at the discourse level when representations obeying the mapping rule are selected.
} 
the same sentence, especially if they have contradictory requirements. That is, if one object is $[+$ presupposed $]$ and $[-$ referential $]$, whereas the other object is [- presupposed $]$ and $[+$ referential], one feature would demand a canonical order and the other feature a scrambled order.

We have seen that $[ \pm$ referential] can regulate the order of Russian objects whenever $[ \pm$ presupposed] is vacuously satisfied and therefore inoperative (see (8)). We have also seen that [ \pm presupposed] can regulate the order of Russian objects (see (4)). What we need to establish is what happens to $[ \pm$ referential] in a sentence like (4), where $[ \pm$ presupposed] is encoded. As it turns out, [ \pm referential] is not encoded in (4) at all. That is, the interpretation of objects with regard to this feature is absolutely free in (4), any configuration being possible. It is even possible to interpret the direct object in (4a) as a nonspecific indefinite and the indirect object as definite/ specific, which would result in twisted mapping onto (9) if [ \pm referential] were encoded. This suggests that when $[ \pm$ presupposed] is operative, it overrides $[ \pm$ referential]; that is, the latter cannot regulate the order of objects if the former is operative.

If we envisage an interpretive hierarchy that the relevant features are ordered on, $[ \pm$ presupposed] must be ranked higher on it than [ \pm referential].

(12) Argument prominence hierarchy (to be revised)

$$
\begin{aligned}
& \text { [ } \pm \text { presupposed] } \\
& \text { [ } \pm \text { referential] }
\end{aligned}
$$

The ranking of features on the argument prominence hierarchy (APH) in (12) illustrates that although both features can regulate the order of objects, lower-ranked [ \pm referential] can do so only when higher-ranked [ \pm presupposed] is inoperative. When both features are inoperative in a sentence, and the order of objects is regulated by the thematic hierarchy, the O-IO order surfaces (see (8a)). From this observation, we conclude that this is the canonical order of objects in Russian. However, let us consider the data in (13).

(13) [What happened?] CONTEXT
a. [FOC Ivan peredal pis'mo agèntu].
S-V-O-IO
Ivan handed letter.ACC agent.DAT
'Ivan handed the letter to an agent.'
b. [FOC Ivan peredal agentu pis'mò].
Ivan handed agent.DAT letter.ACC
S-V-IO-O
'Ivan handed the/a letter to the/an agent.'

Both objects in (13b) being [- presupposed], their construal with regard to [ \pm referential] can correspond to three out of the four possible interpretations: either both carry equal (either negative or positive) values of this feature or the indirect object is [+ referential] and the direct object [-referential]. This means that neither [ \pm presupposed $]$ nor $[ \pm$ referential $]$ is operative in $(13 b)$. Yet it is the marked IO-O order that surfaces. Moreover, the order that we have so far analyzed 
as unmarked is more interpretively restricted in (13). That is, the O-IO order in (13a) is possible only if licensed by transparent mapping onto (9).

Note that in (8) all objects are animate, whereas in (13) the indirect object is animate and the direct object is inanimate. A way to explain the data in (13) is to hypothesize that some other interpretation, such as animacy, licenses the scrambled structure in (13b). The corresponding feature must be ranked lower than [ \pm referential] on the $\mathrm{APH}$, as it regulates the order of objects only when $[ \pm$ referential] is inoperative, as in (13b). When [ \pm referential] is operative, it overrides [ \pm animate] (see (13a)). We can now use the previously outlined mechanism to capture the data in (13).

(14) $[+$ animate $]>[-$ animate $]$

(15) a. $\mathrm{O}_{[+ \text {animate }]} \mathrm{IO}_{[- \text {animate }]}$

b. $\mathrm{O}_{[+ \text {animate }]} \mathrm{IO}_{[+ \text {animate }]}$

c. $\mathrm{O}_{[- \text {animate }]} \mathrm{IO}_{[- \text {animate }]}$

d. $* \mathrm{O}_{[- \text {animate }]} \mathrm{IO}_{[+ \text {animate }]}$

$$
\mathrm{IO}_{[+ \text {animate }]} \mathrm{O}_{[- \text {animate }]}
$$

Hence, the relative prominence of objects is established in (13b) on the basis of [ \pm animate], the scrambled IO-O order being licensed by transparent mapping onto (14). Since [ \pm animate] is overridden by [ \pm referential] in (13a), we conclude that the latter outranks the former (see (17)). That is, the features [ \pm referential] and [ \pm animate] have contradictory requirements in (13a), but transparent mapping onto (9) results in the unmarked order.

(17) Argument prominence hierarchy ${ }^{9}$

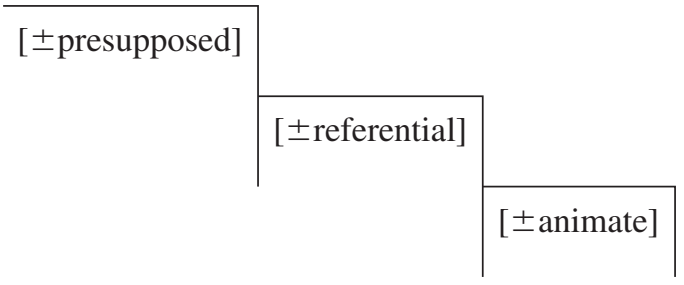

The above observations entail that $[ \pm$ animate $]$ is ranked below $[ \pm$ referential $]$ on the APH, as in (17). ${ }^{10}$ If so, $[ \pm$ presupposed] must outrank [ \pm animate] as well. This prediction is borne

\footnotetext{
${ }^{9}$ The APH in (17) is an adapted version of the Animacy Hierarchy (Silverstein 1976) used to account for word order alternations in languages such as Navajo (Young and Morgan 1987). Silverstein's hierarchy refers to lexical feature specifications of NPs, which makes it too restricted for an analysis that deals with discourse features. Hence, the APH given in (17) must be construed as containing abstract interpretive features.

${ }^{10}$ Transparent mapping onto (1) on the basis of the features on the APH is analyzed here as contributing toward interpretability of a given representation when it is nested in a specific discourse. Thus, placing pragmatically presupposed material before more dynamic nonpresupposed material obeys Communicative Dynamism (Firbas 1964, 1971, 1984, 1992, Sgall, Hajičová, and Panevová 1986). A similar conclusion can be drawn with respect to referentiality; that is, the linear precedence of an argument that denotes a specific referent with respect to an argument that does not (yet) pick out any specific referent can also be seen as contributing toward Communicative Dynamism. The more peculiar case is
} 
out (see (18)). (Henceforth, “\#” appears before sentences that are grammatical but either (a) infelicitous in the given context or (b) felicitous only if additional pragmatic assumptions are made and the required discourse interpretation is accommodated.)

(18) [Who did Ivan hand the letter to?]

a. Ivan peredal pis'mo [FOC agèntu].

S-V-O-IO

Ivan handed letter.ACC agent.DAT

'Ivan handed the/a letter to the/an agent.'

b. \#Ivan peredal [FOC agentu] pis'mò.

S-V-IO-O

Ivan handed agent.DAT letter.ACC

Sentence (18b) is infelicitous in the given context regardless of the interpretation of the objects with respect to $[ \pm$ referential] because $[ \pm$ presupposed] is the highest-ranked feature, and in (18) this feature does not license a marked structure.

Crucially, when all the features on the APH are vacuously satisfied, the O-IO order surfaces. We saw this in a sentence with animate objects in (8a), but we expect the same result with inanimate objects. This prediction is borne out (see (19)). ${ }^{11}$

(19) [What happened?] CONTEXT

a. [FOC Ivan podverg komnatu osmòtru].

S-V-O-IO

Ivan subjected room.ACC inspection.DAT

'Ivan subjected the/a room to the/a inspection.'

presented by the animate interpretation, which treats entities with mental faculties as more accessible than those lacking such faculties. Although the psychological nature of this preference is not entirely clear, it has been observed that animate interpretation facilitates discourse linking. Thus, Vogel and Steinbach (1998) observe that fronted accusative pronouns can only refer to animate entities in German. They conclude that discourse linking of pronouns is easier if the pronoun refers to an animate entity.

Communicative Dynamism is taken here to be a universal principle. However, languages differ with respect to the extent to which they can obey it. Languages that encode thematic relations via morphological case-markers, such as Russian, allow more syntactic flexibility, which makes it possible to obey the principle in a larger number of constructions. However, even languages that are more syntactically restricted, such as English, aim at obeying this principle whenever possible. Thus, Williams (2003) observes that while English unmarked structures can encode focus in a variety of positions, a structure with heavy NP shift is used only when the shifted NP is in focus, suggesting that such a structure must map transparently onto (5). Similarly, English passive constructions are chosen over active sentences whenever the former but not the latter map transparently onto (9) (see (i)).

(i) [What happened?] CONTEXT

a. [FOC John was stung by a wasp!]

b. \#[FOC A wasp stung John!]

${ }^{11}$ A skeptical reader might suggest that the particular word order found in (19) is triggered by the property of the verb podvergat' 'to subject', as in English only the prepositional dative construction and not the double object construction can be found with this verb. However, it is plausible that the double object construction is not available for this verb in English not because of some unexplained property of this verb but because 'to subject' unambiguously selects an inanimate indirect object. That is, even when an animate NP is used as the indirect object of this verb, as in I subjected her to John, it is interpreted as denoting an inanimate concept, such as John's annoying habits. Other English verbs that unambiguously select an inanimate indirect object, such as to restrict and to consign, also resist occurring in double object constructions (Matthew Reeve, pers. comm.). It is therefore plausible that the choice of structure that a ditransitive verb such as to subject occurs in relies on the interpretation of the objects it selects with respect to animacy. If so, the argument that the word order in (19) is licensed by the interpretation of the objects with regard to animacy holds. 

b. [FOC Ivan podverg osmotru kòmnatu].
S-V-IO-O
Ivan subjected inspection.DAT room.ACC
'Ivan subjected a room to the inspection.'

Here, both objects are [- presupposed] and [- animate]. In (19a), [ \pm referential] can be vacuously satisfied, and it is the canonical O-IO order that surfaces. The marked IO-O order in (19b) surfaces only when licensed by mapping onto (9).

The above data strongly support the hypothesis that the canonical order of Russian objects is O-IO, the reversed order being possible only when licensed by an interpretation on the APH. Whenever neither interpretation on the APH is operative, the thematic hierarchy determines the Theme-Goal order. However, any feature on the APH can override the thematic hierarchy, licensing a scrambled Goal-Theme order.

The choice of feature regulating the order of objects is determined by the position of the corresponding interpretation on the APH. Whenever a higher-ranked feature is operative, it overrides all the lower-ranked features; that is, the interpretation of the latter becomes immaterial for the ordering of objects. However, whenever a higher-ranked feature is vacuously satisfied (i.e., the arguments carry equal values of this feature), a lower-ranked feature regulates the order of objects.

Above, I demonstrated that the scrambled S-V-IO-O structure is more restricted in its interpretation than the canonical S-V-O-IO structure (see (2) and (3)). I argued that this fact is predicted by economy considerations on the assumption that the scrambled structure is syntactically costly. The next section investigates the syntax of the Russian S-V-IO-O structure and unfolds an analysis that captures its costly nature.

\section{The Syntax of Neutral Scrambling}

This article is concerned with neutral scrambling, which is characterized by neutral intonation, with the clause-final constituent carrying an intonational contour that falls from a neutral speech level to a lower pitch level. This intonational contour has been referred to in the Russian linguistic literature as IK1 (Bryzgunova 1971, 1981). Along with canonical structures, neutrally scrambled sentences are sometimes analyzed as belonging to so-called nonemotive speech (Yokoyama 1986). A defining characteristic of both types of sentences is that sentential stress is assigned to their most deeply embedded constituent, via the Nuclear Stress Rule. ${ }^{12}$

Neutrally scrambled sentences exhibit properties of A-scrambling (Mahajan 1990). A neutrally scrambled object binds into the other object (see (20b) and (21b) for variable and anaphoric binding) and outscopes it (see $(22 \mathrm{c}-\mathrm{d})) .^{13}$

\footnotetext{
${ }^{12}$ Neutrally scrambled sentences discussed in this article are prosodically distinct from $\bar{A}$-scrambled sentences in that a neutrally scrambled XP always has the option of being unaccented and destressed, whereas an $\bar{A}$-scrambled XP always carries a prominent prosodic marker.

${ }^{13}$ In $(22 b, d)$, the question mark in front of the wide scope reading of the existential quantifier is due to the availability of a specific interpretation of the indefinite, which results in apparent wide scope.

The scope facts in (22) obtain not only in sentences with narrow focus on one of the objects but also in sentences with VP-, vP-, and IP-wide foci.
} 
(20) a. [Who did the secretary introduce every student to?] ConTEXT Sekretarša predstavila každogo studenta ${ }_{1} \quad\left[\mathrm{FOC}_{\mathrm{egO}} \mathrm{eg}_{1}\right.$ učitelju]. secretary introduced every student.ACC his teacher.DAT 'The secretary introduced every student to his teacher.'

b. [Who did the secretary introduce to every teacher? $]_{\text {CONTEXT }}$ Sekretarša predstavila každomu učitelju ${ }_{1} \quad$ [FOC ego $_{1}$ studèntov]. secretary introduced every teacher.DAT his students.ACC 'The secretary introduced to every teacher his students.'

(21) a. [Who did you introduce Masha and Ivan to?] CONTEXT Ja predstavil Mašu i Ivana ${ }_{1}$ [FOC roditeljam drug drùga $a_{1}$. I introduced Masha and Ivan.ACC parents.DAT each other.GEN 'I introduced Masha and Ivan to each other's parents.'

b. [Who did you introduce to Masha and Ivan?] CONTEXT Ja predstavil Maše i Ivanu ${ }_{1}$ [FOC roditelej drug drùga ${ }_{1}$. I introduced Masha and Ivan.DAT parents.ACC each other.GEN 'I introduced to Masha and Ivan the parents of each other.'

(22) a. [Who did the secretary introduce two students to?] CONTEXT Sekretarša predstavila dvux studentov [FOC každomu àvtoru]. secretary introduced two students.ACC every author.DAT 'The secretary introduced two students to every author.'

b. [Who did the secretary introduce every student to?] CONTEXT Sekretarša predstavila každogo studenta [FOC dvum àvtoram]. secretary introduced every student.ACC two authors.DAT 'The secretary introduced every student to two authors.' $\quad \forall>\exists ; ? \exists>\forall$

c. [Who did the/a secretary introduce to two authors?] Sekretarša predstavila dvum avtoram [FOC každogo studènta]. secretary introduced two authors.DAT every student.ACC 'The secretary introduced every student to two authors.'

d. [Who did the/a secretary introduce to every author?]

Sekretarša predstavila každomu avtoru [FOC dvux studèntov]. secretary introduced every author.DAT two students.ACC 'The secretary introduced two students to every author.'

I will henceforth refer to Russian neutral scrambling as A-scrambling. ${ }^{14}$

${ }^{14}$ Although both orders of objects are possible with embedded reciprocals (see (21)), when the reciprocals are not embedded, the O-IO order is perceived as more felicitous than the IO-O order (see (i)). Plausibly, this is the result of an economy condition that blocks scrambled structures because an unmarked structure exists that already captures the required interpretation. This, in turn, lends additional support to the hypothesis that O-IO is the unmarked order of Russian objects.

(i) a. [Who did you introduce the students to? $]_{\text {CONTEXT }}$

Ja predstavil studentov $_{1} \quad\left[\mathrm{FOC}_{\text {drug drùgu }}\right]$.

I introduced students.ACC each other.DAT

'I introduced (the) students to each other.' 
In previous sections, I have hypothesized that the order of Russian objects is regulated by two hierarchies: the thematic hierarchy and the APH. When the two hierarchies misalign, only one type of interpretive prominence (i.e., thematic or IS) can be structurally/linearly represented. In Russian, linear encoding of IS prominence is chosen over linear/structural encoding of thematic prominence. That is, the resulting PF representation linearly encodes IS prominence at the cost of not representing thematic prominence via the linear order of arguments. ${ }^{15}$

The observation that the two hierarchies regulate the surface order of Russian objects can be captured either by assuming that the thematic hierarchy regulates the order in which objects merge, whereas the APH licenses A-movement of the indirect object across the direct object, or by arguing that both hierarchies affect the order in which objects merge, with the APH licensing a reversed order of merger. Both positions have been defended extensively; some scholars postulate that the inverse order of objects involves movement (Larson 1988, Junghanns and Zybatow 1995, King 1995, Bailyn 2003a,b, 2004, Slioussar 2007), and others that both object orders can be base-generated (Bruening 2001, Cuervo 2003, Gračanin-Yuksek 2006, Neeleman and van de Koot 2008, 2012, Pylkkänen 2008, Slavkov 2008, Dvořák 2010, Marvin and Stegovec 2012). Although I take no firm stand here on the question of whether Russian A-scrambling should be analyzed as involving A-movement or variation in the base component, in what follows I adopt the base-generation analysis of object-across-object A-scrambling introduced in Neeleman and van de Koot 2012. While I adopt the base-generation account mainly for presentational convenience, it is worth mentioning that it finds theoretical and empirical support. To be precise, the view that the neutrally scrambled IO-O order involves A-movement runs into (at least) two problems that are intrinsically linked to each other. From the theoretical perspective, A-movement of object NPs across c-commanding object NPs violates Relativized Minimality (Rizzi 1990). ${ }^{16}$ From the empirical point of view, an A-moved indirect object should be able to reconstruct for scope to the position of its trace, which is below the direct object, contrary to fact. That is, we have seen that Russian A-scrambled structures consistently have surface scope along with constructions representing the canonical order of objects (see (22)).

The lack of inverse scope readings in A-scrambled structures is particularly striking when these structures are compared with passive ones such as (23). We have seen that when an existential quantifier A-scrambles across a universal quantifier, as in (22c), only the surface scope reading is possible. In contrast, when an existential quantifier A-moves across a universal quantifier, both scopal readings are available (see (23)).

b. [Who did you introduce to the students? $]_{\text {CONTEXT }}$

?Ja predstavil studentam [FOC $_{1}$ drug drùga ${ }_{1}$.

I introduced students.DAT each other.ACC

'I introduced to the students each other.'

${ }^{15}$ As argued in Titov 2012b, 2013b, the violation of the structural encoding of thematic prominence must be made visible in the PF representation via morphological markers such as morphological case and agreement markers.

${ }^{16}$ In this article, I adopt the stricter version of Relativized Minimality as introduced in Rizzi 1990, where A-movement of argument NPs across c-commanding argument NPs in A-positions is blocked by Relativized Minimality. 
(23) [Dva lektora $]_{1}$ byli uvoleny $t_{1}$ každym universitètom.

two lecturers were fired every university.INSTR

'Two lecturers were fired by every university.'

Sentence (23) is scopally ambiguous. Plausibly, the availability of the inverse scope reading in (23) results from the A-moved indefinite NP reconstructing to the position of the trace left in its thematic complement-to-V position, which is below the VP-adjoined instrumental " $b y$-phrase" hosting the universal quantifier (see (24)). Conversely, the unavailability of the inverse scope reading in (22c) suggests that the structure in (22c) contains no trace of the indirect object below the direct object to which the former could reconstruct. This explains the scope differences between (22c) and (23), which, in turn, makes the base-generation account of Russian A-scrambling more plausible.

(24)

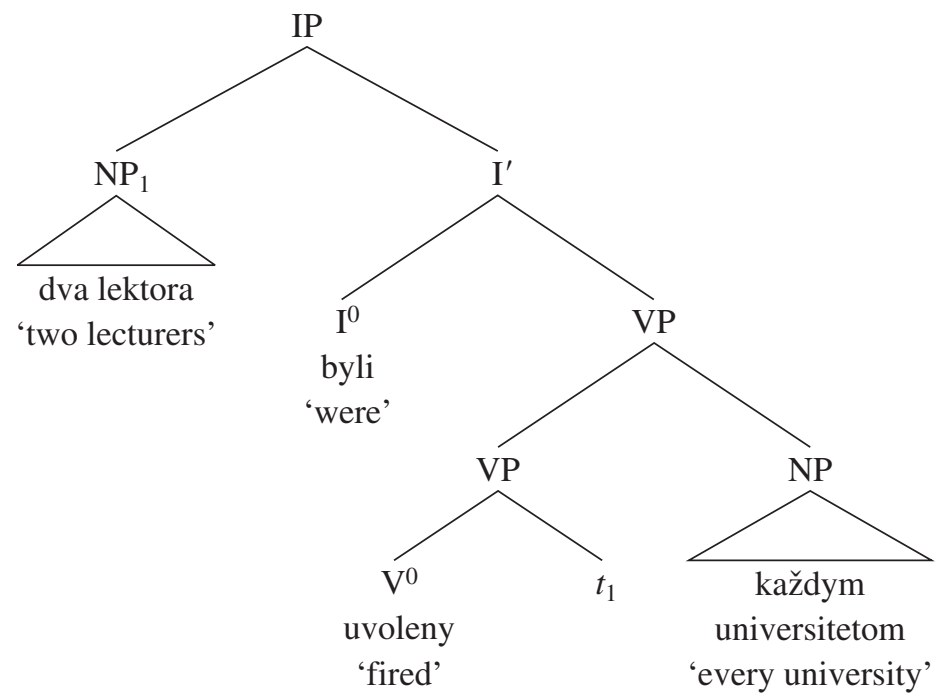

Moreover, while there is psycholinguistic evidence for traces left behind by A-movement (see, e.g., Shetreet and Friedmann 2012), cross-modal priming experiments show that in the case of A-scrambling there is no reactivation of the scrambled object in the position of the potential trace (see van de Koot et al. 2015). This result is of course compatible with the absence of a trace, but poses a challenge for analyses that treat A-scrambling as the result of A-movement.

Neeleman and van de Koot (2012) analyze A-scrambled constructions as base-generated and maintain that base-generated A-scrambled structures are more costly than base-generated canonical structures because the former involve late assignment of a $\theta$-role that is linked to a more complex object in the predicate's ordering tier, as in (25b). The analysis borrows the approach to thematic assignment from Neeleman and van de Koot 2002 where $\theta$-roles are assumed to be features of a predicate that must be ordered in the predicate's $\theta$-grid so as to be distinguished. The fact that the two $\theta$-roles in (25) are linked to distinct positions in the ordering tier distinguishes them and makes them identifiable in copying and mapping to lexical semantics. 
(25) a.

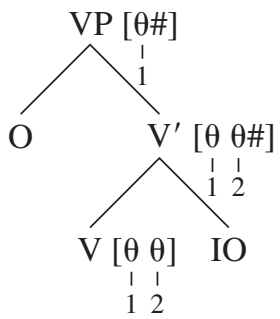

b.



The idea that the least prominent $\theta$-role (i.e., the $\theta$-role linked to the thematically least prominent interpretation) is linked to a more complex object in the ordering tier is based on minimal assumptions about the organization of ordering tiers. In order to generate positions on the ordering tier, construction of a tier requires an atom of some sort as well as a successor function. If we take the categorial feature (e.g., V) as the available atom and call the successor function $f$, the sequence in (26) is generated, every subsequent item on the tier being more complex because it contains an additional instance of the successor function. In (25), the objects to which internal $\theta$-roles are linked are represented in the tree structures as natural numbers. These, however, must be understood as representing the objects in (26).

(26) $1: \mathrm{V}$

2: $f(\mathrm{~V})$

3: $f(f(\mathrm{~V}))$, etc.

A consequence of this analysis is that the orders of projection in the unmarked O-IO structure in (25a) and the scrambled IO-O structure in (25b) are not equally economical. The optimal order of assignment of $\theta$-roles is the one that maximally reduces the content of the projecting predicate (see (25a)). Marked orders, on the other hand, result from the assignment of an "unexpected" $\theta$-role, namely, one whose assignment does not maximally reduce the content of the projecting predicate (see (25b)). Since the less prominent $\theta$-role of the two is linked to a more complex object in the ordering tier, this $\theta$-role should be discharged first. This is because copying the $\theta$ role linked to a less complex object in the predicate's ordering tier is cheaper. As a result, whenever the $\theta$-role linked to a less complex object in the predicate's ordering tier is assigned before the other $\theta$-role, a more complex structure results. The added complexity of the marked IO-O structure in (25b) is particularly visible when we compare that structure with the unmarked structure in (25a), where the $\theta$-role linked to a less complex object in the predicate's ordering tier is assigned after the discharge of the $\theta$-role linked to a more complex object. Unlike the unmarked construction in (25a), (25b) contains an additional copy of a $\theta$-role linked to the more complex object in the tier. ${ }^{17}$ Assuming that $\theta$-role assignment applies under direct domination (Neeleman and van de

\footnotetext{
${ }^{17}$ The analysis in (25) assumes that Russian ditransitive constructions have a VP-shell structure in the spirit of Larson 1988-in other words, that the canonical structure in (25a) is identical to an English right-branching predicate dative construction. This assumption is based on Russian scope and binding facts (see (20)-(22)) (see Bailyn 2012 for more evidence in support of this structure).
} 
Koot 2002), which forces copying of a $\theta$-role to the first node above an argument, the $\theta$-role linked to the more complex object in the ordering tier must be copied to the VP node to be satisfied by the indirect object NP in (25b) ("\#”' signals satisfaction of a $\theta$-role). In (25a), on the other hand, the $\theta$-role linked to the more complex object in the ordering tier is satisfied first. The fact that the $\theta$-role linked to the more complex object in the ordering tier does not have to be copied above the $\mathrm{V}^{\prime}$ node makes the unmarked O-IO structure in (25a) less costly than the marked IO-O structure in (25b).

By economy, the more costly structure in $(25 \mathrm{~b})$ is selected at the postgrammatical level of discourse if and only if it captures an interpretation that the simpler structure in (25a) fails to express. I have argued that the relevant interpretation has to do with the relative interpretive prominence of objects, which is determined on the basis of the interpretations on the APH. Let us briefly look at the representation selection mechanism that applies at the interface between grammar and discourse. Whenever a marked S-V-IO-O representation is passed to the discourse level, the interface system may detect that this structure is more complex than its canonical counterpart. In this case, the S-V-IO-O structure must map transparently onto (1). By hypothesis, the discourse strategy involved in calculating what interpretation determines the relative prominence of arguments follows a number of steps in a top-to-bottom fashion starting with the highestranked constraint on the APH. The strategy's ultimate aim is to filter out illicit representations. Whenever transparent mapping onto (1) fails on the basis of all of the interpretations on the APH, the system rejects the marked S-V-IO-O representation, and the unmarked S-V-O-IO representation is the only representation that can be used for the given truth-conditional and IS interpretation. In other words, the representation used at the discourse level must linearly encode the relative interpretive prominence of objects, if not on the basis of the APH, then on the basis of the thematic hierarchy.

\section{Alternative Approaches}

The above analysis offers interpretive support for the syntactic accounts that demonstrate that $\mathrm{O}-\mathrm{IO}$ is the canonical order of Russian objects, and hence puts pressure on syntactic accounts that claim that the IO-O order is more basic. In this section, we will consider two such accounts and see how the proposed theory deals with them.

\subsection{Evidence from Idiom Formation and Topicalization (Dyakonova 2007)}

Dyakonova (2007) uses evidence from idiom formation and topicalization to demonstrate that the verb forms a constituent with the direct object to the exclusion of the indirect object, a result that she takes, in turn, as evidence that the indirect object occupies a higher structural position. The argument from idioms relies on the observation that idiomatic expressions in Russian typically consist of $\mathrm{V}+\mathrm{O}$ (accusative Theme) and not $\mathrm{V}+\mathrm{IO}$ (dative Goal). Dyakonova uses this observation to support the claim that a Goal argument is projected outside the lexical VP in Russian. 
(27) Saša stroit devuškam glazki.

Sasha makes girls.DAT eyes.ACC

'Sasha flirts with (the) girls.'

(Bailyn 2010:30, (22b))

However, a closer look at Russian idioms that constitute part of a ditransitive verb phrase reveals that the tendency is for a verb to form an idiom with an inanimate object NP rather than a direct object. That is, in ditransitive verb phrases, idioms consisting of $\mathrm{V}+\mathrm{IO}$ are found alongside idioms consisting of $\mathrm{V}+\mathrm{O}$, provided the object $\mathrm{NP}$ that is part of the idiom is inanimate and the object NP that is not part of the idiom is animate (see (28) and (29), respectively). ${ }^{18}$

(28) Oni predali menja/Ivana anafeme. S-V-O-IO they committed me.ACC/Ivan.ACC anathema.DAT 'They damned me/Ivan.'

(29)

Oni podrezali mne/Ivanu kryl'ja. they clipped me.DAT/Ivan.DAT wings.ACC

'They clipped my/Ivan's wings.'

It is beyond the scope of this article to investigate why inanimate objects have a tendency to carry accusative case rather than dative in Russian; what matters is that, while an object NP included in an idiom that is part of a ditransitive verb phrase can be either accusative or dative, it can never be animate, whereas the object NP selected by the predicate that the idiom forms has a very strong tendency to be animate. ${ }^{19}$

(30) ?? Oni predali dver'/veter/čuvstvo anafeme. S-V-O-IO they committed door/wind/feeling.ACC anathema.DAT

(31) ?? Oni podrezali dveri/vetru/čuvstvu kryl'ja. they clipped door/wind/feeling.DAT wings.ACC

Sentences (30) and (31) are semantically odd as they assume that a door, wind, and a feeling have mental faculties. This is particularly striking in the case of (31), as the meaning of this idiom is 'to deprive somebody of the opportunity to expand his or her abilities'. As a result, this idiomatic

\footnotetext{
${ }^{18}$ The object not included in the idiom in (27)-(29) must be [+ animate] unless the idiom is used in an ironic way, similar to the way the verb in (i), which usually selects a [+ animate, + human] object, is used with a [-animate] object.

(i) The drummer murdered the song.

19 Two observations are in order here. First, that idioms consisting of $\mathrm{V}$ and a direct object, as in (29), are more frequent than idioms consisting of $\mathrm{V}$ and an indirect object, as in (28), must be due to the fact that verbs selecting an animate indirect object and an inanimate direct object are more frequent than verbs selecting an inanimate indirect object and an animate direct object. The latter are very rare, whereas the former are even more frequent than verbs selecting two animate or two inanimate objects.

Second, I am assuming that [ \pm animate] only regulates the order in which two NP/DP objects merge in (partly) idiomatic constructions. Whenever one of the objects is a PP, the neutral order of merger is consistently NP/DP-PP, suggesting that it is the categorial distinction that determines the order of merger in such sentences.
} 
predicate consistently selects a [+ animate, + human] object. The idiom in (30) originates from an expression that was used in the Russian Orthodox Church to capture the practice of excommunication, an act of excluding a person from church membership. Since its creation, the idiom has mainly been used with the meaning 'to damn or to condemn somebody', hence with an animate direct object. However, in modern Russian it is marginally possible for this idiomatic predicate to select an inanimate object, such as 'someone's actions', albeit with a distinct meaning, namely, 'to reject something categorically'. Plausibly, at the point this idiom was created, only a [+ animate, + human] direct object could be used, suggesting that the choice of object the verb formed a constituent with in this VP idiom depended on this feature. However, after becoming a fixed expression, this idiomatic predicate has relaxed its selectional restrictions with regard to animacy.

The above observations imply that the choice of the object a ditransitive verb forms a constituent with in a VP idiom depends on the feature [ \pm animate]. Crucially, the availability of V + IO idioms as in (28) undermines Dyakonova's conclusion that a Goal argument is projected outside the lexical VP in Russian.

Apart from idiom formation facts, Dyakonova uses the contrast in topicalization possibilities in (32) to argue that a verb forms a constituent with a Theme argument to the exclusion of a Goal argument.

(32) a. [тор Čitat' skázki $]_{1}$ roditeli detjam očen' ljùbjat $t_{1}$. read.INF tales.ACC parents kids.DAT very like

'Parents like to read (the) tales to (the) kids very much.'

b. ??/*[тор Čitat' détjam $]_{1}$ roditeli skazki očen' ljùbjat $t_{1}$. read.INF kids.DAT parents tales.ACC very like

(Dyakonova 2007:13)

Dyakonova observes that a topicalized phrase that consists of a ditransitive verb and one of its objects can include a direct object but not an indirect object (see (32)). She concludes that the verb merges first with the direct object. The constituent formed by the verb and the direct object can therefore be topicalized. The indirect object, conversely, is merged higher in the structure. Thus, at no stage in the derivation is there a constituent that includes the indirect object and the verb but excludes the direct object, explaining why (32b) is infelicitous.

Two short remarks are in order at this stage. First, it must be noted that (32b) is not strictly speaking ungrammatical. In fact, it's a perfectly well-formed sentence, and we will see later that as long as additional pragmatic assumptions are made, (32b) can fare better than (32a). Moreover, we will see that in some contexts (32a) cannot be used at all. Nevertheless, Dyakonova's observation stands that without any context and any additional pragmatic assumptions, (32a) sounds more natural than $(32 b)$.

The second remark concerns the critique that Dyakonova's analysis has received in the linguistic literature. Dyakonova's proposed analysis of the facts in (32) does not account for Russian V-to-v raising (Bailyn 2010). That is, a ditransitive verb consistently moves across both of its objects in Russian, which means that the structure prior to the topicalization demonstrated in (32) is the one given in (33). 
(33) Roditeli očen' ljubjat čitat' detjam skazki. parents very like read.INF kids.DAT tales.ACC 'Parents like to read (the) tales to (the) kids very much.'

However, in (33) there is no constituent that consists of the ditransitive verb and just one of its objects, suggesting that Dyakonova's analysis cannot be applied to the data in (32). It is therefore plausible that the surface order in (32) is derived via remnant movement. That is, in (32a) the indirect object must have evacuated the vP prior to vP-topicalization, so that the fronted phrase contains a trace of the indirect object.

In what follows, I assume that the first step of the remnant movement operation in (32a) - namely, the evacuation of the indirect object out of the $\mathrm{vP}$-involves A-movement, whereas the topicalization of the vP involves $\bar{A}$-movement. This conclusion is based on the observation that $\overline{\mathrm{A}}$-scrambling is restricted to contrastive categories in Russian (see footnote 7). In line with that, the topicalized $\mathrm{vP}$ is interpreted as contrastive. Conversely, the indirect object is not contrastive, which is why it has to evacuate the contrastive vP (Titov 2012b). Since the indirect object does not cross the direct object, no Relativized Minimality violation occurs.

The observation that only the indirect object can move out of the vP in (32) is readily compatible with the adopted hypothesis that objects are merged in Goal-Theme order in Russian whenever the indirect object is animate and the direct object inanimate (see (16)). However, this does not imply that IO-O order is the canonical order of Russian objects. After all, it is licensed by transparent mapping onto (14).

My proposal makes rather intricate predictions about how topicalization affects sentences where objects have identical values of [ \pm animate]. In this respect, the verb pokazat' 'to show' is of particular interest, as it may take either two objects with identical values of [ \pm animate] (see (34)) or a [+ animate] indirect object and a [- animate] direct object (see (35)).

(34) a. [FOC Učitel' pokazal rebënka vračù]. S-V-O-IO teacher showed child.ACC doctor.DAT

'A/The teacher took a/the child to a/the doctor.'

b. [FOC Učitel' pokazal vraču rebënka]. S-V-IO-O teacher showed doctor.DAT child.ACC

'A/The teacher took a child to the doctor.'

(35) a. [FOC Mal'čik pokazal devočke fìl'm]. S-V-IO-O boy showed girl.DAT film.ACC

'A/The boy showed a/the girl a/the film.'

b. [FOC Mal'čik pokazal fil'm dèvočke]. S-V-O-IO boy showed film.DAT girl.DAT

'A/The boy showed a girl the film.'

In an all-focus context, two animate objects occur in the unmarked O-IO order (see (34a)), the scrambled structure in (34b) being licensed by referentiality encoding. Conversely, the objects in (35) favor a scrambled order licensed by animacy (see (35a)), unless referentiality overrides it (see (35b)). 
Following the adopted hypothesis that A-scrambling is base-generated, the difference in the order of merger in (34) and (35) should be reflected in options for topicalization. This is because the NP that evacuates the vP (i.e., the higher-merged object NP) is a direct object in (34a) but an indirect object in (35a). Hence, the fronted phrase is expected to contain an indirect object in the former case, but a direct object in the latter, unless referentiality overrides this. As shown in (36) and (37), this is the pattern that obtains.

(36) a. [тор Pokazat' vračú $]_{1}$ mat' rebënka xòčet $t_{1}$. show.INF doctor.DAT mother child.ACC wants

'A/The mother wants to take a/the child to a/the doctor.'

b. [тор Pokazat' rebënka $]_{1}$ mat' vraču xočet $t_{1}$. show.INF child.ACC mother doctor.DAT wants

'A/The mother wants to take a child to the doctor.'

(37) a. [тор Pokazat' fíl'm] $]_{1}$ mal'čik devočke xòčet $t_{1}$. show.INF film.ACC boy girl.DAT wants

'A/The boy wants to show a/the film to a/the girl.'

b. [тор Pokazat' dévočke $]_{1}$ mal'čik fil'm xòčet $t_{1}$. show.INF girl.DAT boy film.ACC wants

'A/The boy wants to show the film to a girl.'

The above topicalization data provide strong support for the hypothesis that the order in which objects merge relies on their animacy. As the proposal developed here predicts, (36b) and (37b) are possible only when the order of objects is reversed as a result of referentiality encoding (see the determiner choice in the translation). Crucially, the same observations are true of Dyakonova's examples in (32). That is, (32b) is well-formed if the indirect object 'kids.DAT' is construed as [-referential] and the direct object 'tales.ACC' as [+ referential] (see (38)).

(38) [тор Čitat' détjam $]_{1}$ roditeli éti skazki očen' ljùbjat $t_{1}$. read.INF kids.DAT parents these tales.ACC very like

'Parents like to read these tales to kids very much.'

In (38), a demonstrative pronoun is embedded in the direct object, making it [+ referential]. The sentence is perfectly well-formed provided that the indirect object is construed as referring to children in general rather than to specific children.

Furthermore, since [ \pm animate] is outranked not only by [ \pm referential] but also by [ \pm presupposed], it is expected that [ \pm presupposed] is also capable of reversing the order in which objects merge, thereby affecting which object can be included in the topicalized phrase. This prediction is also borne out. ${ }^{20}$

\footnotetext{
${ }^{20}$ Sentences (39) and (40) have verum focus, that is, focus on the truth value of an utterance that is expressed on the inflection.
} 
(39) [Ljubjat li roditeli rasskazyvat' skazki vzroslym?] CONTEXT

'Do parents like telling tales to adults?'

(Don't know about that but ....)

a. [тор ... čitat' détjam $]_{1}$ roditeli skazki [FOC ljùbjat] $t_{1}$. read.INF kids.DAT parents tales.ACC like

' . . p parents do like to read (the) tales to (the) kids.'

b. \#[тор ... čitat' skázki $]_{1}$ roditeli detjam [FOC ljùbjat] $t_{1}$. read.INF tales.ACC parents kids.DAT like

The order that was illicit in Dyakonova's example (32b) is the only one possible in (39) because in the context presented here the [- animate] direct object is [ + presupposed] and the [ + animate] indirect object is [- presupposed]. Plausibly, despite the difference between the objects in this example with respect to the [ \pm animate] feature, a marked order of the objects is disallowed because the highest-ranked operative feature, [ \pm presupposed], does not license it.

As expected, in a sentence where animacy encoding is not operative, as in (36), [ \pm presupposed] can license a scrambled structure whenever the indirect object is [+ presupposed] and the direct object [- presupposed] (see (40)).

(40) $[\text { Does a/the mother want to dedicate a/the poem to a/the doctor? }]_{\text {CONTEXT }}$ (Don't know about that but ....)
a. [тор $\ldots$ pokazat' rebënka $]_{1}$ mat' vraču [FOC xòčet] $t_{1}$. show.INF child.ACC mother doctor.DAT wants
' . . a a/the mother wants to take a/the child to a/the doctor.'
b. \#[тоР ... pokazat' vračú $]_{1}$ mat' rebënka [FOC xòčet] $t_{1}$. show.INF doctor.DAT mother child.ACC wants

Consequently, the data discussed in Dyakonova 2007 not only support the hypothesis that O-IO is the canonical order of Russian objects, but also illustrate the interaction of the interpretive constraints regulating the order in which arguments merge in Russian, as determined by the $\mathrm{APH}^{21}$

If we maintain that the canonical order of arguments is determined by the thematic hierarchy, then we cannot claim that the IO-O order is canonical, as this order surfaces if and only if it is licensed by an interpretation on the APH. Conversely, when the prominence relations of objects are neutralized on the basis of all of the interpretations on the APH, and the order of objects is determined by the thematic hierarchy, only the unmarked O-IO order is possible.

\footnotetext{
${ }^{21}$ Dyakonova (2009) additionally aims to provide interpretive support for the view that IO-O is the canonical order of Russian objects. However, all of the examples she uses have an animate indirect object and an inanimate direct object. Interestingly, all of Dyakonova's $(2007,2009)$ observations are absolutely correct but because the animacy distinction is not taken into account, the conclusion drawn from them is erroneous.
} 


\subsection{A-Movement Analysis of A-Scrambling (Junghanns and Zybatow 1995)}

Above, we observed that the difference in reconstruction possibilities between passive and Ascrambled constructions suggests that the latter are base-generated. Moreover, a base-generation analysis straightforwardly accounts for the remnant topicalization data discussed in section 4.1. Although this makes the base-generation analysis seem more plausible, if any empirical evidence exists in favor of an A-movement account, it should be considered here.

Junghanns and Zybatow (1995) use the assumed lack of focus spreading in scrambled structures to defend an A-movement analysis of Russian object-across-object scrambling. Their argument is based on the observation that unspecified nouns resist [-referential] interpretation in positions that they analyze as scrambled positions, as in (41b).

(41) a. Odna ženščina podarila mal'čiku jàbloko.

S-V-IO-O one woman gave boy.DAT apple.ACC

'A woman gave a/the boy an/the apple.'

b. Odna ženščina podarila jabloko màl’čiku.

S-V-O-IO one woman gave apple.ACC boy.DAT

'A woman gave the apple to a boy.'

(Junghanns and Zybatow 1995:295)

Junghanns and Zybatow present the difference in the interpretation of the objects with respect to definiteness in (41) as evidence in favor of the unmarked character of the S-V-IO-O order. They analyze (41b) as disrupted by A-movement, which results in the unavailability of the [- referential] interpretation for the direct object (see the determiner choice in the translation).

However, the data in (41) can be accounted for without any reference to movement, as long as the encoding of the feature [ \pm referential] is assumed. Junghanns and Zybatow analyze the sentences in (41) without any context and they are therefore interpreted as all-focus sentences. According to the APH, the highest feature determining the prominence of objects in all-focus sentences is [ \pm referential]. Hence, it is this feature that is capable of overriding lower-ranked [ \pm animate].

Incidentally, the argument order in (41) is indeed affected by [ \pm animate]. That is, the indirect object in (41) carries [+ animate], whereas the direct object carries [-animate]. As the analysis proposed here predicts, the objects are merged in the marked Goal-Theme order in (41a), which is licensed by their prominence relations within the animacy domain. However, [ \pm animate] regulates the relative order of arguments in all-focus contexts only when [ \pm referential] is not operative, as in (41a), where the objects can have identical interpretations with respect to referentiality. Conversely, whenever the inanimate direct object is interpreted as [ + referential] and the animate indirect object as [- referential], as in (41b), a scrambled structure can no longer be licensed, as it fails to reflect the relative prominence of the objects within the higher-ranked referentiality domain. In other words, the fact that an unmarked structure is used in (41b) even though the indirect object is more prominent than the direct object within the animacy domain signals that 
a higher-ranked interpretation prohibits a scrambled structure. In an all-focus context, that interpretation is indeed referentiality.

If the objects in (41) were not affected by animacy encoding, referentiality would be able to license a scrambled structure in an all-focus context, as in (42b).

(42) a. Ivan predstavil devočku màl’čiku.

Ivan introduced girl.ACC boy.DAT

'Ivan introduced a/the girl to a/the boy.'

b. Ivan predstavil mal'čiku dèvočku.

S-V-IO-O

Ivan introduced boy.DAT girl.ACC

'Ivan introduced the boy to a girl.'

The fact that the [-referential] interpretation is readily available for the direct object in (42a) as long as both objects are equally prominent with respect to [ \pm animate] undermines Junghanns and Zybatow's assumption that the unmarked order of objects in Russian is GoalTheme. Moreover, a marked structure, as in (42b), is possible only when the Goal argument is interpreted as more prominent than the Theme argument vis-à-vis [ \pm referential]. Importantly, the Goal argument in (42b) must be interpreted as [+ referential], but this clearly is not the result of a lack of focus spreading; rather, it is the result of referentiality encoding in an all-focus sentence.

If we are right in assuming that (41b) and (42b) are all-focus sentences affected by referentiality encoding, we should expect the focus-background encoding to override referentiality encoding. This prediction is indeed borne out.

(43) [Who did a woman give an apple to? $]_{\text {CONTEXT }}$

Odna ženščina podarila jabloko [FOC màl'čiku].

one woman gave apple.ACC boy.DAT

'A woman gave a/the apple to a/the boy.'

(44) [ Who did Ivan introduce to a boy? $]_{\text {CONTEXT }}$

Ivan predstavil mal'čiku [FOC dèvočku].

Ivan introduced boy.DAT girl.ACC

'Ivan introduced a/the boy to a/the girl.'

In (43) and (44), the order of objects is regulated by [ \pm presupposed]. As expected, the lowerranked [ \pm referential] is not encoded in (43) and (44) at all, so that any configuration of values of this feature is possible. Crucially, the lack of focus spreading in (43) and (44) has no effect on the interpretation of the higher objects with regard to referentiality; the [-referential] reading is readily available.

The facts presented in this section challenge Junghanns and Zybatow's idea that the lack of focus spreading can be used to support the A-movement analysis of neutral scrambling. After all, focus spreading is readily available in A-scrambled structures, and the lack of the [-referential] reading for scrambled objects plausibly results from referentiality encoding and not from a lack of focus spreading. 


\section{Another Scrambling Language: The Case of German}

The hypothesis defended here is that $[ \pm$ animate], $[ \pm$ referential], and $[ \pm$ presupposed] are IS features, each occupying its own position on the APH. All of the above interpretations can potentially be part of the information structure of a sentence, but the relative interpretive prominence of two Russian objects can be regulated by only one of them at a time. This is because the IS features are ranked with respect to each other, their ranking being mirrored by their position on the APH. As a result, whenever a higher-ranked constraint is operative in a sentence, it blocks the application of any lower-ranked constraints, the latter being applicable only when the former is not operative. The highest-ranked IS interpretation that is operative in a sentence either licenses a scrambled structure in case this structure maps transparently onto (1) or disallows such a structure in case the corresponding unmarked structure either maps transparently onto (1) or vacuously satisfies (1). When none of the IS interpretations are operative in a sentence, the order in which arguments merge is regulated by the thematic hierarchy and a scrambled structure is not permitted.

Importantly, there is no overlapping of interpretive constraints in Russian. That is, there are intersections but no entailment: the highest-ranked operative constraint is the one that determines the respective order of two arguments, regardless of interpretive properties ranked lower on the APH. It follows that the association of arguments with these interpretive properties is free.

Interestingly, not all scrambling languages behave exactly like Russian. For instance, German does not allow scrambling of [-referential, + presupposed] objects or of [+ referential, - presupposed] objects. This phenomenon has been called the Indefiniteness Puzzle (Lenerz 1977). In the German examples in (45)-(47), borrowed from Lenerz 2002, only the unmarked Goal-Theme order is felicitous whenever the direct object is interpreted as a nonspecific indefinite. ${ }^{22}$ Examples $(47 b-c)$ are infelicitous only on a nonspecific reading of the scrambled indefinites, strongly suggesting that $[ \pm$ referential] is one of the features licensing German scrambling.

(45) [Whom did you give the book? $]_{\text {CONTEXT }}$

a. Ich habe [FOC dem/einem Studènten] das Buch gegeben.

I have the/a student.DAT the book.ACC given

'I gave the book to the/a student.' = unmarked order

b. Ich habe das Buch [FOC dem/einem Studènten] gegeben.

I have the book.ACC the/a student.DAT given

'I gave the book to the/a student.' = scrambled order

(Lenerz 2002:179, (2))

\footnotetext{
${ }^{22}$ Lenerz (2002) assumes that Goal-Theme is the canonical order of German objects. This position is not shared by everyone. Thus, on the basis of binding facts and weak pronominal ordering after movement to the Wackernagel position, Müller (1998) argues that Theme-Goal is the canonical order of German objects. Moreover, it has been observed that the Theme-Goal order in German is perceived as marked only when the indirect object is animate and the direct object is inanimate (as in Russian). When both objects are animate or inanimate, the Theme-Goal order is perceived as neutral (see Fanselow 1995, Vogel and Steinbach 1995, 1998). Since all of Lenerz's (2002) examples involve an animate indirect object and an inanimate direct object, they do not tell us anything about the orders regulated by the thematic hierarchy, as they are all affected by animacy encoding. However, as this article is concerned with Russian, there's no place in it for a discussion of the nature of the canonical order of German objects. Therefore, I present Lenerz's (2002) analysis here as it is, without questioning his assumptions about the canonical order of objects.
} 
(46) [What did you give to the student?] $]_{\text {CONTEXT }}$

a. Ich habe dem Studenten [FOC das Bùch] gegeben.

I have the student.DAT the book.ACC given

'I gave the book to the student.' = unmarked order

b. \#Ich habe [FOC das Bùch] dem Studenten gegeben.

I have the book.ACC the student.DAT given

'I gave the book to the student.' = scrambled order

(Lenerz 2002:180, (3))

(47) [Whom did you give a book? $]_{\text {CONTEXT }}$

a. Ich habe [FOC dem/einem Studènten] ein Buch gegeben.

I have the/a student.DAT a book.ACC given

'I gave a book to the/a student.' = unmarked order

b. \#Ich habe ein Buch [FOC dem Studènten] gegeben.

I have a book.ACC the student.DAT given

'I gave a book to the student.' = scrambled order

c. \#Ich habe ein Buch [FOC einem Studènten] gegeben.

I have a book.ACC a student.DAT given

'I gave the book to a student.' = scrambled order

(Lenerz 2002:180, (4))

As demonstrated in (45b), scrambling of a [+ referential, + presupposed] direct object is allowed, whereas scrambling of a [+ referential, - presupposed] (see (46b)) or [-referential, + presupposed] (see $47 \mathrm{~b}-\mathrm{c}$ ) direct object is impossible.

We have seen that in Russian, examples of the type given in $(47 b-c)$ are possible. That is, in Russian, A-scrambling can be licensed purely by [ \pm presupposed], the interpretation of arguments with respect to [ \pm referential] being free. Sentence (46b), on the other hand, would be illformed in Russian as well. This is because [ \pm presupposed] overrides [ \pm referential] in Russian. Therefore, even if [ \pm referential] licensed a scrambled structure (i.e., if the object across which scrambling takes place were [- referential] in a Russian example, as it is in the German example in (46b)), [ \pm presupposed] would still override it and demand an unmarked order.

Crucially, German scrambling cannot be licensed by $[ \pm$ referential] even when $[ \pm$ presupposed] is not operative.

(48) [What happened?/What did you do?] CONTEXT

a. [FOC Ich habe [FOC einem Studenten mein Bùch gegeben]].

I have a student.DAT my book.ACC given

'I gave my book to a student.' = unmarked order

b. \#[FOC Ich habe [FOC mein Buch einem Studènten gegeben]].

I have my book.ACC a student.DAT given

'I gave my book to a student.' = scrambled order 
Native speakers of German judge (48b) less felicitous than (48a), suggesting that referentiality alone cannot license A-scrambling in German.

Several analyses have been proposed to account for the Indefiniteness Puzzle in German (see, e.g., Büring's (2000) Optimality Theory analysis). In what follows, I demonstrate how the system proposed here accounts for the data in (45)-(48). Assuming that the APH is universal, we expect the interpretations on this hierarchy to license neutral scrambling crosslinguistically. However, a specific language might make use of more than one linguistic tool to encode a specific feature on the hierarchy. For instance, German, unlike Russian, can use stress shift rather than scrambling to encode [ \pm presupposed] (see (45a)). Plausibly, languages that have the option of prosodic encoding of $[ \pm$ presupposed] put stricter requirements on the interpretation that licenses neutral argument reordering.

The pattern demonstrated in (45)-(48) suggests that German neutral scrambling is licensed by the simultaneous encoding of two features that are adjacent on the APH, namely, [ \pm presupposed] and [ \pm referential]. That is, neither [ \pm presupposed] nor [ \pm referential] can take part in the relative argument-prominence encoding on its own because the transparent mapping onto (1) can only be calculated on the basis of the intersection of these two features.

Although German appears to require both features to be operative in a sentence for scrambling to be licensed, the two features are still ranked with respect to each other. The relative ranking of the two features is reflected in the fact that while the scrambled object must have a positive value with respect to both features, the object across which scrambling takes place need have a negative value only with respect to [ \pm presupposed]. That is, the latter object has a free interpretation with respect to [ \pm referential] (see $(45 b)$ ). This means that both features are operative only with respect to the scrambled object. However, it does not mean that the interpretation of the other object is irrelevant for the mechanism licensing scrambled structures, as [ \pm presupposed] must be operative with respect to this object.

Let us now use the previously outlined mechanism to account for German neutral scrambling.

(49) $[+$ prominent $]>[-$ prominent $]$

(50) a. $\quad \mathrm{IO}_{[+ \text {presupposed }]} \mathrm{O}_{[- \text {presupposed, }- \text { referential }]}$

b. $\mathrm{IO}_{[+ \text {presupposed }]} \mathrm{O}_{[+ \text {presupposed, }}-$ referential $]$

c. $\mathrm{IO}_{[+ \text {presupposed }]} \mathrm{O}_{[- \text {presupposed, + referential }]}$

d. $\mathrm{IO}_{[+ \text {presupposed }]} \mathrm{O}_{[+ \text {presupposed, }+ \text { referential }]}$

e. $\mathrm{IO}_{[- \text {presupposed }]} \mathrm{O}_{[- \text {presupposed, }- \text { referential }]}$

f. $\mathrm{IO}_{[- \text {presupposed }]} \mathrm{O}_{[+ \text {presupposed, }}-$ referential $]$

g. $\mathrm{IO}_{[- \text {presupposed }]} \mathrm{O}_{[- \text {presupposed, + referential }]}$

h. $* \mathrm{IO}_{[- \text {presupposed }]} \mathrm{O}_{[+ \text {presupposed, }}+$ referential $]$

(51)

$$
\mathrm{O}_{[+ \text {presupposed, + referential }]} \mathrm{IO}_{[- \text {presupposed }]}
$$

The simultaneous encoding of two features with regard to the direct object complicates the system, resulting in eight possible configurations instead of four (see (50)). However, as before, the unmarked structure captures the majority of interpretations with regard to the relative interpretive 
prominence of objects, whereas the scrambled structure is used only for the interpretation in (51), which is the interpretation that the unmarked structure fails to express (see (50h)). ${ }^{23}$

Let us look at how the outlined system accounts for the Indefiniteness Puzzle illustrated in (45)-(48). The only sentence in (45)-(48) that allows scrambling is (45b). Excitingly, this is the only sentence that corresponds to the configuration in (51); that is, in (45b) a [+ presupposed, + referential] direct object scrambles across a [- presupposed] indirect object. In the infelicitous example (46b), a [- presupposed, + referential] direct object fails to scramble across a [+ presupposed] indirect object because the relevant configuration is captured by the unmarked structure (see $(50 \mathrm{c}))$. In (47b-c), a [+ presupposed, - referential] direct object fails to scramble across a [- presupposed] indirect object. This configuration is captured by the unmarked structure in (50f). And finally, in (48b) a [-presupposed, + referential] direct object fails to scramble across a [- presupposed] indirect object. This configuration is captured by the unmarked structure in $(50 \mathrm{~g})$.

Hence, all of the infelicitous scrambled sentences in (45)-(48) have the configurations —namely, $(50 \mathrm{c}, \mathrm{f}, \mathrm{g})$ - that are already captured by the unmarked structure, which explains why scrambling is disallowed. We can now predict that scrambling should also be impossible for the configurations in $(50 \mathrm{a}, \mathrm{b}, \mathrm{d}, \mathrm{e})$, as they are also captured by the unmarked structure. This prediction is borne out. ${ }^{24}$

(52) a. [What did you give to the/a student?] $]_{\text {CONTEXT }}$ \#Ich habe [FOC ein Bùch] dem/einem Studenten gegeben. I have a book.ACC the/a student.DAT given

b. [Who gave a book to the/a student? $]_{\text {CONTEXT }}$ \#[FOC Hàns] hat ein Buch dem/einem Studenten gegeben. Hans has a book.ACC the/a student.DAT given

c. [Who gave the book to the/a student? $]_{\text {CONTEXT }}$ \#[FOC Hàns] hat das Buch dem/einem Studenten gegeben. Hans has the book.ACC the/a student.DAT given

d. [What happened?] CONTEXT \#[Foc Hans hat ein Buch dem/einem Studènten gegeben]. Hans has a book.ACC the/a student.DAT given

${ }^{23}$ The configuration in $(50 \mathrm{~h})$ is infelicitous in a sentence like (i) with unmarked prosody where the most deeply embedded object is assigned sentential stress by the Nuclear Stress Rule.

(i) [Who did you give the book to? $]_{\text {CONTEXT }}$ \#Ich habe [Foc dem/einem Studenten] das Buch gegeben.

I have the/a student the book given

This is predicted by the fact that German has the option of encoding IS interpretations prosodically rather than syntactically. It can therefore encode narrow focus on the indirect object via stress shift, as in (45a), or via scrambling, as in (45b). Hence, unlike in Russian, in German a structure requiring twisted mapping onto (1) is impossible only when prosody is unmarked.

${ }^{24}$ As Marta Wierzba (pers. comm.) points out, in (52c) it is difficult to interpret the direct object in the reply, as well as in the German variant of the question, as discourse-new, which in turn affects the judgments. However, as soon as a definite NP that does not require a discourse referent is used, such as War and Peace, the judgments in (52c) hold. 
Sentence (52a) corresponds to the configuration in (50a), (52b) corresponds to (50b), (52c) corresponds to $(50 \mathrm{~d})$, and (52d) corresponds to (50e). All of these configurations are captured by the canonical structure, which explains why a scrambled structure cannot be used for them.

Therefore, the analysis outlined in this article not only successfully accounts for the Indefiniteness Puzzle but also makes further predictions with respect to the interpretations licensing neutral scrambling in German.

\section{Conclusion}

In this article, I have argued that the order in which objects merge in scrambling languages is regulated by two hierarchies: the thematic hierarchy and the APH given in (17). The interpretations on the APH are ranked with respect to each other. In Russian, any lower-ranked interpretation is capable of regulating the order in which objects merge if and only if all the higher-ranked interpretations are inoperative. Whenever none of the interpretations on the APH are operative, the order in which objects merge is regulated by the thematic hierarchy, resulting in the canonical Theme-Goal order.

The interpretations on the APH are capable of licensing scrambled structures not only in Russian but also in other scrambling languages. However, languages differ with respect to how many such interpretations are required in order to license scrambling.

\section{Appendix: Russian Data}

The examples in this article are my own unless indicated otherwise. Judgments regarding Russian sentences were obtained from native speakers via personal meetings. In all, 18 female and 3 male speakers were interviewed. Of the female consultants, four were aged 30-39, ten 40-49, one 50-59, two 60-69, and one 70-79. Of the male consultants, one was aged 50-59, one 60-69, and one 70-79. Most consultants were nonlinguists who come from Moscow and St. Petersburg. They were instructed that they would be presented with question/answer pairs. Their task was to determine whether a sentence was compatible with the given context under the reading where neither of the object referents was known to the speaker or the hearer. Before each sentence, a contextual question was read aloud to the consultants, with particular attention to keeping the prosodic pattern neutral. Truth-conditionally identical sentences showing variation in the order of objects were paired up. The respective ordering of sentences with IO-O and O-IO orders varied randomly to avoid priming bias. When consultants judged a sentence to be incompatible with the given context, and judged a sentence with the opposite object order to be more felicitous, they were asked whether further assumptions about the referentiality status of objects could render the former sentence felicitous. If the answer was negative, the prosodic pattern was manipulated to include topic intonation on the linearly first object. The consultants were then asked whether that change had an effect on their judgment.

Following Junghanns and Zybatow (1995), this article uses bare NPs to illustrate the syntactic encoding of [ \pm referential] because the construal of bare NPs with regard to referentiality is determined solely on the basis of their structural position. NPs that are morphologically specified 
for (non)specificity are not discussed for the following reasons. First, morphologically indicated specificity often has a fine-grained structure that cannot be described with a binary feature (Farkas 1995, von Heusinger 2007). As a result, speakers have unclear judgments about whether a morphologically specified NP should be construed as referential. For instance, one way to mark Russian NPs as (non)specific is to use the pronominal determiners wh-to and koe-wh, the former signaling that the referent is not identifiable by the speaker and the latter indicating epistemic specificity (Haspelmath 1997). However, a wh-to indefinite can be anchored to a referent introduced by a subject NP (Geist 2008), in which case it is construed as referential. Moreover, some speakers reject sentences containing koe-wh objects altogether (anonymous LI reviewer), plausibly because such NPs refer to a singleton set, which is an interpretation that is not easily accommodated. Second, morphological specification of (non)specificity often results in a phonologically complex NP, which makes it difficult to keep this NP unaccented and destressed. This, however, is a necessary condition on ensuring that we are dealing with A-scrambling and not $\bar{A}$-scrambling licensed by interpretations other than those discussed in this article (see footnotes 7 and 12). Discrepancies in judgments resulting from the above factors are illustrated in table 1.

\section{Table 1}

Discrepancies in judgments. $I_{A}$ stands for judgments provided by the author's informants; $I_{R}$, for judgments provided by an anonymous $L I$ reviewer's informant; $I_{R 6}$, for judgments provided by the reviewer's informant six months later; and $R$, for the reviewer's judgments. $\checkmark$ stands for compatible with the context; \#, for compatible if and only if additional assumptions with regard to the referentiality status of objects are made; and *, for impossible with neutral intonation.

Context: What happened?

\begin{tabular}{|c|c|c|c|c|}
\hline $\begin{array}{l}\text { Example } \\
\begin{array}{ll}\text { a. Ivan peredal kakomu-to agentu kakogo-to špiòna. } \\
\text { Ivan handed some agent.DAT some spy.ACC } \\
\text { 'Ivan handed some spy to some agent.' } \quad=\text { scrambled }\end{array}\end{array}$ & $\begin{array}{l}\mathrm{I}_{\mathrm{A}} \\
\#\end{array}$ & $\begin{array}{l}\mathrm{I}_{\mathrm{R}} \\
\#\end{array}$ & $\begin{array}{l}\mathrm{I}_{\mathrm{R} 6} \\
\checkmark\end{array}$ & $\mathrm{R}$ \\
\hline $\begin{array}{l}\text { b. Ivan peredal kakomu-to agentu ètogo špiòna. } \\
\text { Ivan handed some agent.DAT this spy.ACC } \\
\text { 'Ivan handed this spy to some agent.' } \quad \text { scrambled }\end{array}$ & $*$ & $\#$ & $\checkmark$ & \\
\hline $\begin{array}{l}\text { c. Ivan peredal kakogo-to špiona ètomu agèntu. } \\
\text { Ivan handed some spy.ACC this agent.DAT } \\
\text { 'Ivan handed some spy to this agent.' } \quad \text { canonical }\end{array}$ & $\#$ & $\checkmark$ & $\checkmark$ & \\
\hline $\begin{array}{l}\text { d. Ivan peredal ètomu agentu kakogo-to špiòna. } \\
\text { Ivan handed this agent.DAT some spy.ACC } \\
\text { 'Ivan handed some spy to this agent.' } \quad=\text { scrambled }\end{array}$ & $\checkmark$ & $\#$ & $\checkmark$ & \\
\hline $\begin{array}{l}\text { e. Ivan peredal bolee desjatka pisem ètomu agentu. } \\
\text { Ivan handed more ten.GEN letters.GEN this agent.DAT } \\
\text { 'Ivan handed more than ten letters to this agent.' = canonical }\end{array}$ & $*$ & & & $\checkmark$ \\
\hline
\end{tabular}


Provided that the sentences in table 1 have neutral intonation, my consultants judge (a) to be incompatible with an all-focus context unless the objects are construed such that the referent of the indirect object is known to the referent of the subject but the referent of the direct object is not, which is an unlikely but in principle possible construal. My consultants judge (d) as more felicitous than (c) in the given context, whereas the reviewer's consultant seems undecided about the referentiality status of the indirect object in (c,d), interpreting it as referential at first (i.e., its referent is known to the referent of the subject) but changing his or her mind about it six months later for the scrambled sentence in $(\mathrm{d})$.

My consultants judge $(\mathrm{b}, \mathrm{e})$ to be impossible with neutral intonation in the given context. Incidentally, (e) sounds unnatural without a rise-fall topic contour IK3 (Bryzgunova 1971, 1981) on pisem, plausibly because of the phonological complexity of the direct object.

\section{References}

Antonyuk-Yudina, Svitlana. 2010. Scope freezing, scrambling and QR in Russian. Ms., Stony Brook University, Stony Brook, New York.

Bailyn, John F. 2003a. Does Russian scrambling exist? In Word order and scrambling, ed. by Simin Karimi, 156-176. Oxford: Blackwell.

Bailyn, John F. 2003b. A (purely) derivational account of Russian scrambling. In Formal Approaches to Slavic Linguistics 11: The Amherst meeting 2002, ed. by Wayles Browne, Ji-Yung Kim, Barbara H. Partee, and Robert A. Rothstein, 41-62. Ann Arbor: Michigan Slavic Publications.

Bailyn, John F. 2004. Generalized Inversion. Natural Language and Linguistic Theory 22:1-49.

Bailyn, John F. 2010. What's inside VP? New (and old) evidence from Russian. In Formal Approaches to Slavic Linguistics 18: The second Cornell meeting 2009, ed. by Wayles Browne, Adam Cooper, Alison Fisher, Esra Kesici, Nikola Predolac, and Draga Zec, 21-37. Ann Arbor: Michigan Slavic Publications.

Bailyn, John F. 2012. The syntax of Russian. Cambridge: Cambridge University Press.

Bruening, Benjamin. 2001. QR obeys Superiority: Frozen scope and ACD. Linguistic Inquiry 32:233-273. Brun, Dina. 2001. Information structure and the status of NP in Russian. Theoretical Linguistics 27:109-135. Bryzgunova, Elena. 1971. O smyslorazličitel'nyx vozmožnostjax russkoj intonacii. Voprosy jazykoznanija 4:42-51.

Bryzgunova, Elena. 1981. Zvuk i intonatsija russkoj rechi. Moscow: Russkij jazyk.

Büring, Daniel. 2000. What do definites do that indefinites definitely don't? Ms., UCLA, Los Angeles, CA. Chomsky, Noam. 1995. The Minimalist Program. Cambridge, MA: MIT Press.

Chvany, Catherine. 1975. On the syntax of BE-sentences in Russian. Cambridge, MA: Slavica.

Cuervo, Cristina. 2003. Datives at large. Doctoral dissertation, MIT, Cambridge, MA.

Dahl, Östen. 1970. Some notes on indefinites. Language 46:33-41.

Dikken, Marcel den. 2006. Relators and linkers: The syntax of predication, predicate inversion, and copulas. Cambridge, MA: MIT Press.

Dvořák, Věra. 2010. On the syntax of ditransitive verbs in Czech. In Formal Approaches to Slavic Linguistics 18: The second Cornell meeting 2009, ed. by Wayles Browne, Adam Cooper, Alison Fisher, Esra Kesici, Nikola Predolac, and Draga Zec, 161-177. Ann Arbor: Michigan Slavic Publications.

Dyakonova, Marina. 2007. Russian double object constructions. ACLC Working Papers 2:3-30.

Dyakonova, Marina. 2009. A phase-based approach to Russian free word order. Doctoral dissertation, University of Amsterdam.

Fanselow, Gisbert. 1995. Scrambling and anti-scrambling. Paper presented at the workshop "The Role of Economy Principles in Linguistic Theory,"' Berlin. 
Fanselow, Gisbert, and Denisa Lenertová. 2011. Left peripheral focus: Mismatches between syntax and information structure. Natural Language and Linguistic Theory 29:169-209.

Farkas, Donka. 1995. Specificity and scope. In Actes du Premier Colloque Langues et Grammaire, ed. by Léa Nash and George Tsoulas, 119-137. Paris: University of Paris VIII.

Firbas, Jan. 1964. On defining the theme in functional sentence analysis. Travaux linguistiques de Prague $1: 267-280$.

Firbas, Jan. 1971. On the concept of communicative dynamism in the theory of functional sentence perspective. Sborník prací filozofické fakulty brněnské univerzity A 19:135-144.

Firbas, Jan. 1984. Carriers of communicative dynamism. Prague Studies in English 18:63-73.

Firbas, Jan. 1992. Functional sentence perspective in written and spoken communication. Cambridge: Cambridge University Press.

Geist, Ljudmila. 2008. Specificity as referential anchoring: Evidence from Russian. In Proceedings of Sinn und Bedeutung 12, ed. by Atle Grønn, 151-164. Oslo: University of Oslo.

Gračanin-Yuksek, Martina. 2006. Double object construction in Croatian: Arguments against $\mathrm{Appl}^{0}$. In Formal Approaches to Slavic Linguistics 15: The Toronto meeting 2006, ed. by Richard Compton, Magdalena Goledzinowska, and Ulyana Savchenko, 94-112. Ann Arbor: Michigan Slavic Publications.

Haspelmath, Martin. 1997. Indefinite pronouns. Oxford: Oxford University Press.

Ioup, Georgiette. 1977. Specificity and the interpretation of quantifiers. Linguistics and Philosophy 1: $233-245$.

Junghanns, Uwe, and Gerhild Zybatow. 1995. Syntax and information structure of Russian clauses. In Formal Approaches to Slavic Linguistics 4: The Cornell meeting 1995, ed. by Wayles Browne, Ewa Dornisch, Natasha Kondrashova, and Draga Zec, 289-319. Ann Arbor: Michigan Slavic Publications.

King, Tracy Holloway. 1995. Configuring topic and focus in Russian. Stanford, CA: CSLI Publications.

Larson, Richard K. 1988. On the double object construction. Linguistic Inquiry 19:335-391.

Lenerz, Jürgen. 1977. Zur Abfolge nominaler Satzglieder im Deutschen. Tübingen: TBL Verlag Gunter Narr.

Lenerz, Jürgen. 2002. Scrambling and reference in German. In Issues in formal German(ic) typology, ed. by Werner Abraham and C. Jan-Wouter Zwart, 179-192. Amsterdam: John Benjamins.

Mahajan, Anoop. 1990. The A/A-bar distinction and movement theory. Doctoral dissertation, MIT, Cambridge, MA.

Marvin, Tatjana, and Adrian Stegovec. 2012. On the syntax of ditransitive sentences in Slovenian. Acta Linguistica Hungarica 59:177-203.

Müller, Gereon. 1998. Optimality, markedness, and word order in German. Ms., Universität Tübingen.

Neeleman, Ad. 1994. Complex predicates. Doctoral dissertation, Utrecht University.

Neeleman, Ad, and Tanya Reinhart. 1998. Scrambling and the PF interface. In The projection of arguments, ed. by Miriam Butt and Wilhelm Geuder, 309-353. Stanford, CA: CSLI Publications.

Neeleman, Ad, and Kriszta Szendrői. 2004. Superman sentences. Linguistic Inquiry 35:149-159.

Neeleman, Ad, and Elena Titov. 2009. Focus, contrast, and stress in Russian. Linguistic Inquiry 40:514-524.

Neeleman, Ad, and Hans van de Koot. 2002. The configurational matrix. Linguistic Inquiry 33:529-574.

Neeleman, Ad, and Hans van de Koot. 2008. Dutch scrambling and the nature of discourse templates. Journal of Comparative Germanic Linguistics 11:137-189.

Neeleman, Ad, and Hans van de Koot. 2012. Theta theory: In defense of Plan B. Ms., University College London.

Pereltsvaig, Asya. 2003. Syntax of denominal and ditransitive verbs reconsidered. Ms., University of Sheffield.

Pylkkänen, Liina. 2008. Introducing arguments. Cambridge, MA: MIT Press.

Reinhart, Tanya. 1995. Interface strategies. OTS Working Papers in Linguistics TL-95-002. Utrecht: Utrecht University. 
Reinhart, Tanya. 1999. Strategies of anaphora resolution. OTS Working Papers. Available at http://www.let .uu.nl/ $\sim$ tanya.reinhart/personal/.

Reinhart, Tanya. 2004. Topics and the conceptual interface. In Context dependence in the analysis of linguistic meaning, ed. by Hans Kamp and Barbara Partee, 275-305. Amsterdam: Elsevier.

Reinhart, Tanya. 2006. Interface strategies: Optimal and costly computations. Cambridge, MA: MIT Press.

Rizzi, Luigi. 1990. Relativized Minimality. Cambridge, MA: MIT Press.

Sgall, Petr, Eva Hajičová, and Jarmila Panevová. 1986. The meaning of the sentence in its semantic and pragmatic aspects. Dordrecht: Kluwer.

Shetreet, Einat, and Naama Friedmann. 2012. Stretched, jumped, and fell: An fMRI investigation of reflexive verbs and other intransitives. Neuroimage 60:1800-1806.

Silverstein, Michael. 1976. Hierarchy of features and ergativity. In Grammatical categories in Australian languages, ed. by R. M. W. Dixon, 112-171. Canberra: Australian Institute of Aboriginal Studies.

Slavkov, Nikolay. 2008. Formal consequences of dative clitic doubling in Bulgarian ditransitives: An applicative analysis. Journal of Slavic Linguistics 16:139-166.

Slioussar, Natalia. 2007. Grammar and information structure: A study with reference to Russian. Doctoral dissertation, Utrecht University and St. Petersburg State University.

Soschen, Alona. 2005. Derivation by phase: Russian applicatives. In Proceedings of the 2005 Canadian Linguistic Association Annual Conference, ed. by Claire Gurski. Available at http://westernlingu istics.ca/Publications/CLA-ACL/Soschen.pdf.

Szendrői, Kriszta. 2001. Focus and the syntax-phonology interface. Doctoral dissertation, University College London.

Titov, Elena. 2012a. Encoding focus and contrast in Russian. In The syntax of topic, focus and contrast: An interface-based approach, ed. by Ad Neeleman and Reiko Vermeulen, 119-155. Berlin: Mouton de Gruyter.

Titov, Elena. 2012b. Information structure of argument order alternations. Doctoral dissertation, University College London.

Titov, Elena. 2013a. Do contrastive topics exist? Journal of Linguistics 49:413-454.

Titov, Elena. 2013b. Scrambling and interfaces. In Information structure: Empirical perspectives on theory, ed. by Felix Bildhauer and Mira Grubic, 33-55. Potsdam: Universitätsverlag Potsdam.

van de Koot, Hans, Renita Silva, Claudia Felser, and Mikako Sato. 2015. Dutch A-scrambling is not movement: Evidence from antecedent priming. The Linguistic Review 32:739-776.

Vogel, Ralf, and Markus Steinbach. 1995. On the (absence of a) base position for dative objects in German. FAS Working Papers in Linguistics 4:99-131.

Vogel, Ralf, and Markus Steinbach. 1998. The dative - an oblique case. Linguistische Berichte 173:65-90. von Heusinger, Klaus. 2007. Referentially anchored indefinite NPs. In Existence: Syntax and semantics, ed. by Ileana Comorovski and Klaus von Heusinger, 273-292. Dordrecht: Springer.

Williams, Edwin. 2003. Representation Theory. Cambridge, MA: MIT Press.

Yokoyama, Olga. 1986. Discourse and word order. Amsterdam: John Benjamins.

Young, Robert W., and William Morgan. 1987. The Navajo language: A grammar and colloquial dictionary. Albuquerque: University of New Mexico Press.

University College London

Room 101

Chandler House

2 Wakefield Street

London WC1N IPF

United Kingdom

e.titov@ucl.ac.uk 
